Clinical Study

\title{
Preliminary results of 45 patients with trigeminal neuralgia treated with radiosurgery compared to hypofractionated stereotactic radiotherapy, using a dedicated linear accelerator
}

\author{
Mario Francesco Fraioli ${ }^{a, *}$, Lidia Strigari ${ }^{b, c}$, Chiara Fraioli ${ }^{c}$, Mario Lecce ${ }^{a}$, Damiano Lisciani ${ }^{a}$ \\ a Department of Neurosciences, Neurosurgery, Via Oxford 81, University of Rome Tor Vergata, Rome 00133, Italy \\ ${ }^{\mathrm{b}}$ Department of Medical Physics and Expert Systems, Regina Elena Institute, Rome, Italy \\ ${ }^{\mathrm{c}}$ Department of Radiotherapy, C I RAD Villa Benedetta, Rome, Italy
}

\section{A R T I C L E I N F O}

Article history:

Received 14 September 2011

Accepted 2 November 2011

\section{Keywords:}

Hypofractionated stereotactic radiotherapy Radiosurgery

Retrogasserian target

Trigeminal neuralgia

\begin{abstract}
A B S T R A C T
Radiosurgery (RS) and hypofractionated stereotactic radiotherapy (HSRT) were performed in 23 and 22 patients respectively for the treatment of trigeminal neuralgia. RS and HSRT were performed with a dedicated linear accelerator (LINAC): an invasive frame (for RS) or a relocatable stereotactic frame fitted with a thermoplastic mask and bite blocks (HSRT) were used for positioning patients. The RS treatment delivered $40 \mathrm{~Gy}$ in a single fraction, or for HSRT, the equivalent radiobiological fractionated dose - a total of $72 \mathrm{~Gy}$ in six fractions. The target (the retrogasserian cisternal portion of the trigeminal nerve) was identified by fusion of CT scans with 1-mm-thick T2-weighted MRI, and the radiant dose was delivered by a 10 -mm-diameter cylindrical collimator. The results were evaluated using the Barrow Neurological Institute pain scale during follow-up (mean 3.9 years). The 95\% isodose was applied to the entire target volume. After RS (23 patients), Class 1 results were observed in 10 patients; Class II in nine, Class IIIa in two, Class IIIb in one, and Class V results in one patient. Facial numbness occurred in two (8.7\%) patients, and the trigeminal neuralgia recurred in two patients (8.7\%). Following HSRT (22 patients), Class I results were achieved in eight patients, Class II in eight, Class IIIa in four, and Class IIIb in two patients; recurrence occurred in six (27.5\%), and there were no complications. Thus, both RS and HSRT provided effective and safe therapy for the treatment of trigeminal neuralgia. Patients who underwent RS experienced better pain relief and a lower recurrence rate, whereas those who underwent HRST had no side effects, and in particular, no facial numbness.
\end{abstract}

(c) 2012 Elsevier Ltd. All rights reserved.

\section{Introduction}

Radiotherapy has been used in the treatment of trigeminal neuralgia since the discovery of X-rays. ${ }^{1}$ Radiosurgery now is performed using the Gamma-Knife (Elekta, Stockholm, Sweden) ${ }^{2-5}$ Cyberknife (Accuray, Sunnyvale, CA, USA $)^{6,7}$ or dedicated linear accelerator (LINAC) $)^{8,9}$ delivering high doses in a single fraction to the root entry zone. The reported results have been satisfactory with sensory facial impairment and complications being relatively infrequent.

We aimed to assess whether radiosurgery (RS) at 40 Gy or hypofractionated stereotactic radiotherapy (HSRT) at the radiobiologically equivalent dose, delivered to the retrogasserian cisternal portion of the trigeminal nerve, resulted in effective pain control with a reduced rate of side effects, particularly facial numbness, when compared with the more commonly recommended RS at

\footnotetext{
* Corresponding author. Tel.: +39 06 20903057; fax +39 0620903056.

E-mail address: b.fraioli@libero.it (M.F. Fraioli).
}

$70 \mathrm{~Gy}$ to $90 \mathrm{~Gy}$. Since 2005, Pollock et al. ${ }^{4}$ have recommended a dose reduction to $76 \mathrm{~Gy}$, particularly for repeat RS, to decrease the morbidity of RS in the treatment of trigeminal neuralgia.

We present our results in a series of 45 patients with idiopathic trigeminal neuralgia treated using RS ( $40 \mathrm{~Gy}$ ) or HSRT (radiobiologically equivalent to $40 \mathrm{~Gy}$ in single fraction) using a dedicated LINAC.

\section{Methods and materials}

All 45 patients had been treated previously for trigeminal neuralgia with medical therapy that was either ineffective or had become so over time. The patients were reviewed over a mean follow-up time of 3.9 years (median 3.1 years; range 2.25.2 years). Three patients had been previously treated elsewhere: one with microvascular decompression and subsequent gasserian ganglion glycerolrhizolysis; one with gasserian ganglion balloon compression; and another with microvascular decompression. 
The patients ranged in age from 56 years to 81 years. The trigeminal neuralgia involved: the second division in 21 patients; the second and third divisions in 14 patients; the first and second divisions in six patients; and the third division only in four patients. All patients were advised that the therapeutic effect occurred several weeks after treatment and that medication taken before treatment would continue until gradually reduced over two to five months, depending on their pain.

In 23 patients, RS was performed using a single fraction of $40 \mathrm{~Gy}$ to the isocenter, while in 22 patients, HSRT was delivered using six daily fractions of $12 \mathrm{~Gy}$ (radiobiologically equivalent to a single fraction of $40 \mathrm{~Gy}$ ) to reach a total dose of $72 \mathrm{~Gy}$, according to the linear quadratic model. ${ }^{10,11}$ An $\alpha / \beta$ value of $2.5 \mathrm{~Gy}$ was assumed (that is, the $\alpha / \beta$ of normal tissue).

\subsection{Technology and technique}

RS and HSRT techniques were performed using the following Elekta equipment: Precise LINAC with multileaf, cylindrical collimators (10 mm diameter), i-view GT Electronic Portal Image Device, invasive or relocatable stereotactic frame. The photons used for dose delivery were $6 \mathrm{MV}$.

The selected target was the retrogasserian cisternal portion of the trigeminal nerve. The CT scan and MRI images were fused using the Ergo tool (Elekta) and based on stereotactic frame coordinates. The target was identified and contoured on a high-resolution, 1.5Tesla MRI (Supplementary Fig. 1a) (1-mm-thick, T2-weighted three-dimensional spoiled gradient echo pulse sequence) and the organs-at-risk were contoured on fused 1-mm-thick CT-MRI images (Supplementary Fig. 1b). RS or HSRT LINAC was based on multiple ( 4 or 5 ) equally spaced arcs (Supplementary Fig. 2) delivered through cylindrical collimators to produce a nominally spherical dose distribution focused on the isocenter. The dose calculation grid was $1 \mathrm{~mm}^{3} \times 1 \mathrm{~mm}^{3} \times 1 \mathrm{~mm}^{3}$. The radiation dose of $40 \mathrm{~Gy}$ for RS or $72 \mathrm{~Gy}$ for HRST was chosen according to the selected target and the distribution of the dose in relation to the surrounding structures. The total volume of the target was included in the isodose of $95 \%$. The radiation dose adsorbed by the surrounding neurological and vascular structures was very low.

The dose adsorbed by the surrounding structures, particularly the intracavernous portion of the internal carotid artery (ICA), was carefully evaluated in each patient. The maximum adsorbed dose ranged from $8 \mathrm{~Gy}$ to $12 \mathrm{~Gy}$, which is <30 Gy, the supposed maximum tolerated dose for the intracavernous ICA following RS. ${ }^{12,13}$ The dose adsorbed by the pons following RS or HSRT was particularly low, ranging from $1 \mathrm{~Gy}$ to $4 \mathrm{~Gy}$. The pain outcome was assessed using the Barrow Neurological Institute (BNI) pain intensity scale. ${ }^{2}$ Patients rated with Class I pain were defined as pain free and having had successful treatment; patients in Class II had occasional pain but did not need medication; patients in Class IIIa had no pain, but continued to take medication; patients in Class IIIb had pain that was adequately controlled with medication; patients in Class IV had some pain reduction, but considered the pain relief to be inadequate; and the treatment for patients in Class $\mathrm{V}$ was considered a failure.

All patients underwent a brain MRI one year after treatment.

\section{Results}

BNI pain scores (Table 1) were evaluated using a series of clinical examinations (patients were periodically tested for facial sensitivity and questioned regarding pain recurrence, pain improvement, absence of pain, and facial paresthesias) at three, six, and 12 months after treatment, after which, telephone interviews were performed once per year. MRI performed more than one year after treatment did not show any changes in signal intensity of the trigeminal nerve or the surrounding structures.

\subsection{Radiosurgery}

Ten patients had BNI Class I results; nine had Class II; two had Class IIIa, and one had Class IIIb pain relief. Class V results were observed in one patient who had already been treated with microvascular decompression in another institution. Two recurrences $(8.7 \%)$ occurred during an average follow-up period of 4.1 years. Pain relief occurred after an average of 10.4 days. Two patients $(8.7 \%)$ developed facial numbness at two days and four days respectively after the procedure.

\subsection{Hypofractionated stereotactic radiotherapy}

Eight patients had BNI Class I pain relief, eight had Class II, four had Class IIIa, and two had Class IIIb. Six recurrences (27.3\%) occured in a mean follow-up period of 3.1 years. No complications occurred. Pain relief occurred after an average of 19.6 days.

\section{Discussion}

Many therapies have been proposed for the treatment of medically refractory trigeminal neuralgia: anatomically destructive methods, including retrogasserian rootlet thermocoagulation ${ }^{14-16}$, and percutaneous balloon compression; ${ }^{17}$ and anatomically nondestructive methods, including gasserian ganglion glycerolrhizolysis, ${ }^{18,19}$ and microvascular decompression. ${ }^{20}$ Non-invasive procedures are also performed, including various types of RS. We agree with Onofrio ${ }^{16}$ that: "each procedure has its advocates, but the very multiplicity of choices indicates that none is totally satisfactory".

The choice of RS using $40 \mathrm{~Gy}$ (and consequently $72 \mathrm{~Gy}$ for HSRT) and the $10-\mathrm{mm}$ collimator was tailored to the selected target. According to one anatomical study ${ }^{21}$, the diameter of the retrogasserian portion of the trigeminal nerve is larger than that of the root entry zone, due to reduced compaction of its fibers as they divide into the first, second, and third division of the gasserian ganglion. For this reason, we propose that the trigeminal nerve is more resistant to RS at the root entry zone than at the retrogasserian portion. In our experience, targeting the retrogasserian portion of the nerve, the length of the irradiated nerve is important. Thus, we propose that $40 \mathrm{~Gy}$ at the retrogasserian target will be sufficient to achieve a satisfactory therapeutic effect, rather than the $70 \mathrm{~Gy}$ to $90 \mathrm{~Gy}$ required at the root entry zone. Moreover, the $40 \mathrm{~Gy}$ dose is also appropriate to the isodose line and to the toler-

Table 1

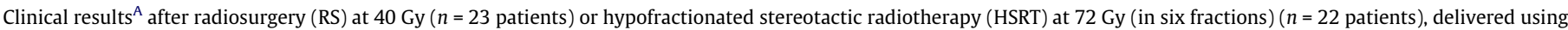
a dedicated linear accelerator, for trigeminal neuralgia

\begin{tabular}{|c|c|c|c|c|c|c|c|c|}
\hline Pain category ${ }^{\mathrm{B}}$ : & BNI I & BNI II & BNI IIIa & BNI IIIb & BNI IV & BNI V & Recurrence & Facial numbness \\
\hline RS & 10 & 9 & 2 & 1 & - & 1 & 2 & 2 \\
\hline HSRT & 8 & 8 & 4 & 2 & - & - & 6 & - \\
\hline
\end{tabular}

\footnotetext{
A Average follow-up time $=3.9$ years.

в $\mathrm{BNI}=$ Barrow Neurological Institute pain intensity scale.
} 
ance of the surrounding normal tissue. In particular, the trigeminal ganglion is adjacent to the intracavernous and petrous carotid artery, and the retrogasserian rootlets and entry zone to superior cerebellar (SCA) and the antero-inferior cerebellar arteries (AICA). Modern techniques allow a dramatic reduction of the dose delivered outside the target, however several studies concerning the effects of RS performed on neoplastic lesions lying very close to important vascular structures emphasize that vascular complications should not be underestimated, particularly for the cavernous carotid artery. ${ }^{12,13}$

Facial sensory disturbances did not occur in patients treated with HSRT whereas they occurred in two patients treated by RS. The choice of RS or HSRT is important in this regard. RS was used in all patients with severe neuralgia, whereas we offered RS, or the alternative HSRT, to patients affected by moderate neuralgia, specifying that RS achieved a higher success rate but a higher rate of side effects (facial numbness in particular). Alternative HSRT treatment was offered because, in our experience, when trigeminal neuralgia is very severe, ablative methods ${ }^{14}$ that cause facial sensory deficits are well accepted. However, deficits in sensation or other side effects are less well tolerated by patients when the neuralgia is sporadic or not severe, and in these patients, HSRT may be helpful.

\section{Conclusions}

RS at 40 Gy and HSTR at 72 Gy was an effective treatment for idiopathic trigeminal neuralgia. RS resulted more effective pain control than HSRT, with a minor rate of recurrence, and with rare facial numbness, which did not occur after HSRT. Further experience is required to choose between RS at $40 \mathrm{~Gy}$ or HSRT for individual patients. We agree with the hypothesis that both methods have a neuromodulatory effect rather than causing damage to the trigeminal nerve. $^{22}$

\section{Conflict of interest/disclosures}

The authors declare that they have no financial or other conflicts of interest in relation to this research and its publication.

\section{Appendix A. Supplementary material}

Supplementary data associated with this article can be found, in the online version, at http://dx.doi.org/10.1016/j.jocn.2011.11.036.

\section{References}

1. Artico M, De Caro GM, Fraioli B, et al. 1897-celebrating of the centennialHermann Moritz Gocht and radiation therapy in the treatment of Trigeminal neuralgia. Acta Neurochir (Wien) 1997;139:761-3.

2. Cheuck AV, Chin LS, Petit JH. Gamma knife surgery for trigeminal neuralgia: outcome, imaging, and brainstem correlates. Int J Radiat Oncol Biol Phys 2004;60:537-41.

3. Little AS, Shetter AG, Shetter ME, et al. Long-term pain response and quality of life in patients with typical trigeminal neuralgia treated with gamma knife stereotactic radiosurgery. Neurosurgery 2008;63:915-24.

4. Pollock BE, Foote RL, Link MJ, et al. Repeat radiosurgery for idiopathic trigeminal neuralgia. Int J Oncol Bio Phys 2005;61:192-5.

5. Régis J, Metellus P, Hayashi M, et al. Prospective controlled trial of gamma knife surgery for essential trigeminal neuralgia. J Neurosurg 2006;104:913-24.

6. Lim M, Villavicencio AT, Burneikiene S, et al. CyberKnife radiosurgery for idiopathic trigeminal neuralgia. Neurosurg Focus 2005;18:E9.

7. Romanelli P, Heit G, Chang SD, et al. Cyberknife radiosurgery for trigeminal neuralgia. Stereotact Funct Neurosurg 2003;81:105-9.

8. Chen JC, Girvigian M, Greathouse H. Treatment of trigeminal neuralgia with linear accelerator radiosurgery: initial results. J Neurosurg 2004;101:346-50.

9. Smith ZA, De Salles AA, Frighetto L, et al. Dedicated linear accelerator radiosurgery for the treatment of trigeminal neuralgia. $J$ Neurosurg 2003;99:511-6.

10. Dale RG. The application of the linear-quadratic dose-effect equation to fractionated and protracted radiotherapy. Br J Radiol 1985;58:515-28.

11. Fowler JF. The linear-quadratic formula and progress in fractionated radiotherapy. Br J Radiol 1989;62:679-94.

12. Shin M, Kurita $H$, Sasaki $T$, et al. Stereotactic radiosurgery for pituitary adenoma invading the cavernous sinus. J Neurosurg 2000;93:2-5.

13. Thomas C, Witt MD. Stereotactic radiosurgery for pituitary tumors. Neurosurg Focus 2003;14. Article 10 .

14. Fraioli MF, Cristino B, Moschettoni L, et al. Validity of percutaneous controlled radiofrequency thermocoagulation in the treatment of isolated third division trigeminal neuralgia. Surg Neurol 2009;71:180-3.

15. Sweet WH, Wepsic JG. Controlled thermocoagulation of trigeminal ganglion and rootlets for differential destruction of pain fibers: Part 1. Trigeminal neuralgia. J Neurosurg 1974;40:143-56.

16. Onofrio BM. Radiofrequency percutaneous gasserian ganglion lesions. Results in 140 patients with trigeminal pain. J Neurosurg 1975;42:132-9.

17. Skirving DJ, Dan NG. A 20 -year review of percutaneous balloon compression of the trigeminal ganglion. I Neurosurg 2001;94:913-7.

18. Hakanson S. Trigeminal neuralgia treated by the injection of glycerol into the trigeminal cystern. Neurosurgery 1981;9:638-46.

19. Chen L, Xu M, Zou Y. Treatment of trigeminal neuralgia with percutaneous glycerol injection into Meckel's cavity: experience in 4012 patients. Cell Biochem Biophys 2010;58:85-9.

20. Mc Laughlin MR, Jannetta PJ, Clyde BL, et al. Microvascular decompression of cranial nerves: lessons learned after 4400 operations. J Neurosurg 1999;90:1-8.

21. Rhoton AL. The anterior and middle cranial base. Neurosurgery 2002;51(Suppl. 1): 273-302.

22. Régis J, Carron R, Park M. Is radiosurgery a neuromodulation therapy?: A 2009 Fabrikant award lecture. J Neurooncol 2010;98:155-62. 